\title{
АФРИКАНСКОЕ ЯЗЫКОЗНАНИЕ
}

УДК 94(38).09

\section{Язык суахили в афроамериканской культуре}

\section{Н.В.Громова}

Московский государственный университет им. М. В. Ломоносова, Российская Федерация, 125009, Москва, ул. Моховая, 11

Для цитирования: Громова Н.В. Язык суахили в афроамериканской культуре // Актуальные проблемы мировой политики. Вып.10 / под ред. Т.С.Немчиновой. СПб.: Изд-во С.-Петерб. ун-та, 2020. С. 144-153. https://doi.org/10.21638/11701/26868318.09

В статье рассматривается роль языка суахили в Африке и США и использование лексики суахили в афроамериканской культуре, в частности в проведении фестиваля афроамериканского праздника Кванзаа, создателем которого является американский историк Маулана Каренга. Также уделяется внимание идеологии афроцентризма и замене "рабских» имен на суахилийские. Отмечаются особенности применения языка суахили при наименовании афроамериканских боевых искусств.

Ключевые слова: язык суахили, панафриканизм, афроцентризм, афроамериканская культура, боевые искусства.

В 2016 г. мир отмечал 50-летний юбилей афроамериканского Рождества Кванзаа (или Кванза), который празднуется с 26 декабря по 1 января. С каждым годом Кванзаа становится все более популярным праздником. Кроме США, отмечается в Канаде, государствах Карибского бассейна, Бразилии, Великобритании и других странах, где существуют диаспоры чернокожих американцев, предками которых были рабы, вывезенные из Африки. В 2006 г. праздник отмечали 28 млн, в 2009 г. уже 30 млн человек ${ }^{1}$.

Отцом-инициатором праздника Кванзаа стал известный историк, профессор, заведующий отделом черных исследований (Black Studies) Университета штата Калифорния, теоретик и один из лиде-

${ }^{1}$ Kwanzaa History. http://www.tike.com/celeb-kw.htm. 
ров движения панафриканизма Маулана Каренга², призывавший совершить культурную революцию, вернуться к африканским истокам в соответствии с идеей о центральном месте Африки в мировой истории и культуре. Он основал общественную организацию «Мы» с молодежным крылом Simba wachanga («Молодые львы»). В 1966 г. предложил воссоздать древний праздник урожая, характерный, по его мнению, для ряда цивилизаций черной Африки.

Названия праздника и его этапов заимствованы из языка суахили. Почему именно суахили? Потому что это наиболее известный и самый крупный африканский язык, с богатой историей и литературой, идентифицируется как символ консолидации, идентичности и единства Африки. Неоднократно раздавались призывы о его использовании в качестве панафриканского. С призывом превратить в общеафриканский тингва франка выступали многие деятели культуры, например, лауреат нобелевской премии Воле Шоинка (в 1970-х годах), известный ганский писатель Айи Квеи Арма (в 1985 г.) и другие. Совет министров Организации Африканского Единства еще в 1986 г. принял резолюцию об использовании суахили в качестве языка общения на континенте [1, p.21]. В настоящее время он является рабочим языком Африканского союза и Африканского парламента. На конференциях, например, в Дар-эс-Саламе (Танзания) в 2000, 2005 и 2012 гг. принимались обращения к правительствам государств Восточноафриканского сообщества (ВАС) и стран региона Великих озер, других стран Африки о целесообразности использования суахили в качестве единого языка всей Африки [2, р.81] и предлагались пути решения этой задачи. Суахили уже выполняет функции межрегионального языка организации Восточноафриканское сообщество (ВАС), воссозданной в 2000 г. в составе Танзании, Кении, Уганды, Руанды и Бурунди, к которой в ближайшем будущем могут присоединиться Малави и Конго. Цель ВАC - единая валюта, полная политическая федерация и использование языка суахили на всех уровнях коммуникации. В статье под названием "Challenges facing the E.A.political federation” («Вызовы, стоящие перед Восточноафриканской политической федерацией»), опубликованной в ведущей угандийской газете New Vision, отмеча-

2 Рональд Эверетт Маккинли родился в 1941 г. в штате Мэриленд, четырнадцатый ребенок в семье баптистов. Он известен под разными псевдонимами: как Рон, Рон Эверетт, Гуссейн, - а наиболее известный его псевдоним - Маулана Каренга. В 1960-е гг. он присоединился к движению Black power. 
ется, что одним из вызовов, стоящих перед ВАС, является проблема общего языка для населения Восточной и Центральной Африки: «Еще одна проблема - это принятие единого языка для Восточной Африки. У Кении и Танзании уже есть общий язык, в то время как Уганда, Руанда и Бурунди используют и английский, и французский, и суахили. Для языка суахили это импульс, чтобы стать катализатором интеграции» ${ }^{3}$.

В последнее время вновь поднимается вопрос о статусе и будущем суахили как панафриканского языка. В октябре 2012 г. в Дар-эсСаламском университете состоялась Международная конференция, посвященная 50-летию изучения суахили, который позиционируется как язык африканского освобождения (African liberation), объединения (unification) и возрождения (renaissance). Именно поэтому М. Каренга выбрал язык суахили [3].

Суахили, наиболее распространенный африканский язык в мире, имеет особую привлекательность в афроамериканских сообществах как символ африканской идентичности. Преподавание африканских языков, в том числе суахили, началось в США в 1958 г. как реакция на возрастающие настроения чернокожего американского населения в поисках истоков их собственной истории ${ }^{4}$. Движение, возглавляемое М.Каренгой, способствовало продвижению языка суахили как учебного предмета. В настоящее время его изучение постоянно растет в Америке [4, p.538]. Увеличилось число средних школ, сейчас их более ста. Сегодня изучение африканского языка, такого как суахили, позволяет поступить в вуз и получить высшее образование. Существуют даже специальные платные курсы для учителей. Такое значительное место суахили в Америке связано не только с образованием, но и с восточноафриканскими диаспорами, многочисленными ассоциациями и суахилийскими церквями (общинная церковь суахили, общество Umoja («Единство») в Миннесоте, Ассоциация общин Танзании и др.) [5, р. 16]. И М.Каренга, и М. Асанте [6, р. 6] $]^{5}$ изучали суахили, но, к сожалению, в использу-

${ }^{3}$ Challenges facing the E. A.political federation // New Vision (Uganda's leading daily), 2012, jan. 31. P. 28.

${ }^{4}$ Один из призывов Uјаmаa слово харамбээ (Harambee («а ну-ка!», «взяли!») - призыв к совместному действию), которое используется для оказания взаимной помощи, например, путем сбора денег на учебу или лечение и т. п.

${ }^{5}$ Молефе Кенте Асанте - профессор кафедры афроамериканских исследований Темпльского университета Филадельфии, идеолог афроцентризма. Его книга «Афроцентризм» (1989) стала своего рода библией афроцентристов. 
емый ими глоссарий вкрались некоторые неточности. В частности, своему имени М. Каренга придает смысл «учитель» или «хранитель традиций», но ни в языке суахили, ни в зулу и шона нет такого слова.

Название праздника Кванзаа имеет две этимологии:

- часть словосочетания matunda ya kwanza - первые плоды. Как считает М. Каренга, праздник «первых фруктов / плодов» отмечался в древней Нубии в эпоху фараонов, в средневековых африканских государствах йоруба и ашанти; он ссылается также на сельскохозяйственные фестивали, которые обычно следуют за первыми урожаями;

- слово $\boldsymbol{k w a n z a}$ в суахили - это инфинитивная форма глагола начинать и отглагольное существительное начало.

К названию древнего праздника Кванза М. Каренга добавил еще одну букву а для «благозвучия», чтобы придать ему афроамериканский колорит или чтобы в нем было семь букв в соответствии с семью основополагающими принципами этого праздника. Кстати, создатель этой новогодней афроамериканской традиции Рональд Мак-Кинли Эверетт изменил свое имя, полученное при рождении, на Маулана ${ }^{6}$ Ндабезита Каренга, что в переводе с суахили значит Maulana - «(наш. - Aвm.) Бог, повелитель; мой господин», Ndabezita на языке зулу - это обращение к верховному вождю зулусов «Мой король» ${ }^{7}$, Karenga - «хранитель традиций». Жены М. Каренги также заменили свои имена на суахилийские: его первая жена взяла себе имя Tiamoyo - «воодушевляй, вдохновляй», вторая жена стала называть себя Нaiba - «красота, привлекательность» ${ }^{8}$. Кстати, его примеру переименования собственного имени последовал основатель движения и идеологического направления афроцентризма 9 Артур Ли Смит, считавший М. Каренгу своим предшественником и единомышленником. Он заменил свое "рабское имя» на Acaнmе Mолефи. Molefi на языке сото означает «тот, кто чтит и хранит традиции», Asante «правитель» (название традиционного правителя

${ }^{6}$ В русских публикациях первое имя Каренги приводится неправильно Молана, в языке суахили каждая гласная произносится раздельно, то есть Маулана. Слово karenga не зафиксировано в словарях суахили.

7 Луцзков А. Д. Зулу-русский словарь. M.: URSS, 2014. 288 с.

${ }^{8}$ Kwanzaa History. http://www.tike.com/celeb-kw.htm.

${ }^{9}$ Афроцентризм - ответная реакция афроамериканцев и африканцев на длившуюся из поколения в поколение униженность, угнетение, европейское высокомерие, имперский расизм $[6$, с. 18]. 
ашанти) заимствованного из языка тви и созвучного суахилийскому слову asante. Многие афроамериканцы выбирают африканские имена для своих детей, особенно из языка суахили, например Ngoma «барабан», Maisha «жизнь», Haki «право» и др. Из языка суахили заимствуется также много названий для различных обществ (Mambo Foundation «фонд «Дела»), фамилий (имя журналиста Tutashinda «Мы победим») и многие другие.

Основу рождественского праздника Кванзаа составляют nguzo saba (семь опор/основ ${ }^{10}$ ) - семь социально-духовных принципов жизни и общинной африканской философии (communitarian African philosophy). Свою философскую позицию М. Каренга назвал Kawaida (обычай, традиция), она была выработана в рамках движения Black Power. В ее основе история, духовность и этика, социальная организация, политическая организация, экономическая организация, художественное и литературное творчество. Возглавляемый им научный институт называется Kawaida Institute for Pan-African Studies, он существует уже почти полвека. Под эгидой института ежегодно проводятся конференции с участием активистов, интеллектуалов и сторонников панафриканизма и афроцентризма.

М. Каренга считал число семь минимальным. В своей социальной и личной жизни черный человек должен следовать таким постулатам:

1. Umоја (единство) - принцип сохранения нераздельности семьи, общества, нации и расы;

2. Kujichagulia (самоопределение) - принцип самоопределения африканской личности, самоидентификации, самоутверждения и самовыражения;

3. Ujima (взаимопомощь, взаимовыручка) - принцип коллективного труда, чувства братского локтя и совместного решения проблем;

4. Uјатаa (совместная экономика, африканский социализм) принцип совместной экономической деятельности, поддержки «черного» бизнеса, «черной» экономики, получение доходов на благо всего общества ${ }^{11}$;

${ }^{10}$ Karenga M. The Nguzo Saba (The Seven Principles). http://www.officialkwanzaawebsite.org-/NguzoSaba.shtml.

11 Один из призывов Uјатаа - слово харамбээ (см. Прим. 4 к настоящей стаmbe). 
5. Nia (цель, перспектива) - принцип максимального развития личности ради возрождения традиционного величия африканца;

6. Кuumba (созидание, творчество, креативность) - принцип развития творческого потенциала каждого человека с тем, чтобы сделать общество лучше и благотворнее, чем то, которое досталось в наследство черному человеку;

7. Imani (вера) - принцип полной веры в афроамериканский народ, его учителей, родителей, лидеров, в справедливость идей и вера в победу в борьбе за справедливость.

Атрибутика и церемониал праздника Кванзаа также имеют суахилийские названия. Празднование сопровождается очень точным церемониалом для каждого из семи дней празднования. Комната или место проведения празднества украшается различными Bendera (флагами, постерами), на которых изображены семь принципов Кванзаа. Участники праздника ежедневно обсуждают один из семи основных принципов, а 1 января завершается дискуссией по поводу седьмого принципа Imani.

Стол накрывается зеленой скатертью, на которую кладут Mkeka (циновку) из соломы, сизаля, хлопка и т. п. Африканская циновка это символ связи с африканскими предками (подобные циновки широко используются также в современной Африке).

На стол ставится семисвечник Kinara (подсвечник), в котором зажигается каждый день по одной свече в течение семи дней праздника. В нем Mishumaa saba (семь свечей) разных цветов: в центре одна черная, символизирующая цвет кожи африканца / афроамериканца, три красных (символ борьбы) и три зеленых (символ надежды).

На праздничном столе обязательно должны быть Маzaо (плоды, фрукты), которые соответствуют ассортименту африканских фруктов (апельсины, лимоны, манго, бананы и др.) и свежих овощей (ямс, бананы, сладкий картофель и др.), Muhindi (кукурузный початок), который можно заменить колоском по одному колоску для каждого ребенка; Zawadi (подарок / подарки) специально для детей, обычно дарят книгу или что-либо, напоминающее африканские традиции; Kikombe cha Umoja (чаша / кубок единства). Именно из этой общей чаши все члены семьи и гости пьют воду - символ источника жизни, единения семьи и общины. 
Начиная с 26 декабря афроамериканцы, отмечающие Кванзаа, приветствуют друг друга на языке суахили фразой Habari gani? (Как дела?), ответное приветствие звучит как Nzuri (Хорошо / прекрасно) или традиционное Kwanzaa yenu iwe ya heri (Счастливой вам Кванзы!).

Шестой день Кванзы предназначен для праздничного ужина Kwanzaa Karamu (пир Кванзаa), на котором напитки распиваются из чаши единства, передаваемой по кругу из рук в руки.

В последний седьмой день начинается официальное действие на улицах города - карнавал. В центре площади ставится большая корзина с фруктами и овощами. Открывается карнавал действом Kukaribisha (приглашение, радушный прием), одним из этапов карнавала является Kuchunguza tena (еще одно поучение / изучение), когда почетные гости и заслуженные люди беседуют с простыми афроамериканцами или африканцами.

Все участники праздничного мероприятия кладут свои фрукты в общую корзину, которая после праздника будет оставлена для всех желающих. В конце праздника раздается призыв Kushangilia (ликование) и произносится Tamshi la tambiko (слово / речь о жертвоприношении). Разумеется, речь не идет о приношении жертв, это действие сводится к Kutoa Jina (называнию имени) - вспоминаются имена предков и разных племен Африки. При этом чаша наполняется чистой водой. Вначале немного воды из чаши выливается на четыре стороны света, что символизирует единство всего человечества.

Затем следует Ngoma (барабан или традиционный танец), когда под барабанный бой все участники праздника танцуют, обнимаются, братаются. Большинство участников церемониала одеты в восточно- или западноафриканские национальные костюмы. Когда барабаны замолкают, звучит Tamshi la tutanara (речь о чем-то; слова tutanara нет ни в языке суахили, ни в зулу), своеобразный гимн, который и завершает 1 января празднование афроамериканского Нового года:

For the Motherland - the black cradle of civilization!

For their ancestors and their unquenchable spirit!

For the elders, from whom we all learn!

For the young who own tomorrow!

For our struggle and in memory of those who fell in it! 
For the unity with which we are guided!

For the creator who created everything big and small! ${ }^{12}$

Перевод:

За Родину - черную колыбель цивилизации!

За предков и их неугасаемый дух!

За старших, от которых мы всему учимся!

За молодых, которым принадлежит завтра!

За нашу борьбу и в память о тех, кто в ней пал!

За единство, которым мы руководствуемся!

За создателя, сотворившего все большое и малое!

При этом различные песни Кванзаа, в том числе и детские, в которые включаются суахилийские слова, составляют значительную часть программы празднования, например:

- Seven days to celebrate Kwanzaa («Семь дней для празднования Кванзаа»);

- Seven days of the Nguzo saba («Семь дней семи принципов»);

- Seven days of the Kinara («Семь дней на подсвечнике»);

- Seven days to remember who we are («Семь дней, чтобы вспомнить, кто мы такие»);

- Kukaribisha Kwanzaa («Приглашать Кванзаа»);

- Kukumbuka Kwanza («Вспоминать Кванзаа»);

- Kushangilia Kwanzaa («Приветствовать Кванзаа»);

- Come celebrate Kwanzaa («Приходите праздновать Кванзаа»).

Язык суахили используется также в Северной и Южной Америке для наименований спортивных состязаний и боевых искусств. Одним из них является капоэйра - афро-бразильский вид боевого искусства, ведущий свое происхождение от субкультуры африканского национального танца и включающий элементы боевой техники рабов из Судана, Анголы и Мозамбика. Названия многих видов боевых искусств ${ }^{13}$ состоят из набора суахилийских слов, зачастую не связанных грамматическим согласованием, например: african kimarekani kutia ngumi (афро-американский бокс) буквально «поамерикански ставить кулак»; kiungo cha mkono (зажим руки); mshindi vita sanaa (победитель боевых искусств), должно быть mshindi wa

12 http://www.history.com/minisites/kwanzaa.

${ }^{13}$ www.intermartialarts.com/membergroups/african-martial-arts; African Martial Arts. www.melanet.com/kwanzaa/whatis.html. 
vita ya sanaa; kimya njia (путь молчаливого воина) - здесь нарушение синтаксических норм, правильно njia ya kimya (путь молчания) и др.

Несмотря на то что М.Каренга называл Кванзаа традиционным африканским праздником, описание этого праздника и его семи основополагающих принципов показывает, что они имеют мало общего с африканскими празднованиями. По большей части они являются чисто американским творением, которое не отражает ничего конкретного в культуре суахили, в этом празднике наблюдается смешение обычаев разных этносов Африки и придуманных М.Каренгой традиций [6]. При этом лексикон фестиваля Кванзаа и боевых искусств не всегда является исконно суахилийским, часто наблюдается нарушение грамматических норм суахили и интерференция с английским языком. Тем не менее суахили как символ афроцентризма продолжает «сотрясать весь мир» ${ }^{14}$ и способствует укреплению межкультурного диалога между африканцами и афроамериканцами.

\section{Литература}

1. Ryanga S. The African Union in the Wake of Globalization: the Forgotten Language Dimension // KISWAHILI, 2002, vol. 65.

2. Mulokozi M. M. Mustakbali wa Kiswahili katika ukanda wa Maziwa Makuu (Будущее языка суахили в регионе Великих Озер) // MULIKA. Dar es Salaam, 2009, no. 28 .

3. Karenga M. Kwanzaa: Origin, Concepts, Practice. Los Angeles: Kawaida Publications, $1977.56 \mathrm{p}$.

4. Temu M.L.N. African American Students' Self-awareness through Kiswahili Language // Journal of Black Studies, 1992, vol. 22, no. 4. Jun. P. 532-545.

5. Ferrari A. Revendicatif Afro-Americain et commentaires de locuteurs Swahili sur la celebration Kwanzaa // Swahili Forum 18 (2011). Universität Leipzig, Institut für Afrikanistik, 2011. 246 p.

6. Давидсон А., Филатова И. Исторические пласты афроцентризма // Pax Africana: континент и диаспора в поисках себя [Текст]: сб. научн. ст. / отв. ред. А.Б. Давидсон; М.: ИД Гос. ун-та - Высш. Шк. экономики, 2009. С.6-41. https://www.hse.ru/data/2010/05/17/1218259309.

Контактная информация:

Громова Нелли Владимировна - д-р филол. наук, проф.; gromova@iaas.msu.ru

${ }^{14}$ Kiswahili sasa chatikisa duniani (Язык суахили теперь сотрясает весь мир) // UHURU, 2012, Okt. 12; см. также [2]. 


\section{Swahili language in Afro-American culture}

\section{Nelli V. Gromova}

Lomonosov Moscow State University,

11, Mokhovaya str., Moscow, 125009, Russian Federation

For citation: Gromova N. V. Swahili language in Afro-American culture. Digest of World Politics, vol.10, ed. by T.S. Nemchinova, St. Petersburg, St. Petersburg State University Press, 2020, pp. 144-153.

https://doi.org/10.21638/11701/26868318.09 (In Russian)

The article examines the role and functions of Swahili language in Africa and the USA, and using the vocabulary of Swahili in the Afro-American culture, particularly in the Afro-American festival of Kwanzaa, which founder is the American historian Maulana Karenga. Attention is also paid to ideology of Afrocentrism and replacing 'slave' names by Swahili names. Features of application of Swahili language in the names of the Afro-American martial arts are registered.

Keywords: Swahili language, panafricanism, Afrocentrism, Afro-American culture, martial arts.

\section{References}

1. Ryanga S. The African Union in the Wake of Globalization: the Forgotten Language Dimension. KISWAHILI, 2002, vol. 65.

2. Mulokozi M. M. Mustakbali wa Kiswahili katika ukanda wa Maziwa Makuu. MULIKA. Dar es Salaam, 2009, no. 28.

3. Karenga M. Kwanzaa: Origin, Concepts, Practice. Los Angeles, Kawaida Publications, $1977.56 \mathrm{p}$.

4. Temu M.L. N. African American Students' Self-awareness through Kiswahili Language. Journal of Black Studies, 1992, vol. 22, no. 4, Jun., pp. 532-545.

5. Ferrari A. Revendicatif Afro-Americain et commentaires de locuteurs Swahili sur la celebration Kwanzaa. Swahili Forum 18 (2011). Universität Leipzig, Institut für Afrikanistik, 2011. 246 p.

6. Davidson A., Filatova I. Historical layers of Afrocentrism. Pax Africana: The Continent and Diaspora in Finding Yourself. Sb. nauchn. st. / ed. by A.B. Davidson. Moscow, Higher School of Economics Press, 2009, pp.6-41. https://www.hse.ru/ data/2010/05/17/1218259309. (In Russian)

Author's information:

Nelli V. Gromova — Dr. Sci. in Philology, Professor; gromova@iaas.msu.ru 